\title{
Los pequeños y medianos agricultores necesitan y pueden volverse muchísimo más eficientes
}

\section{Small and medium farmers require and may become much more efficient}

\section{Polan Lacki}

Curitiba Paraná Brasil, Polan.Lacki@uol.com.br, Polan.Lacki@onda.com.br (55-41) 3243-2366: www.polanlacki.com.br, www.polanlacki.com.br/agroesp

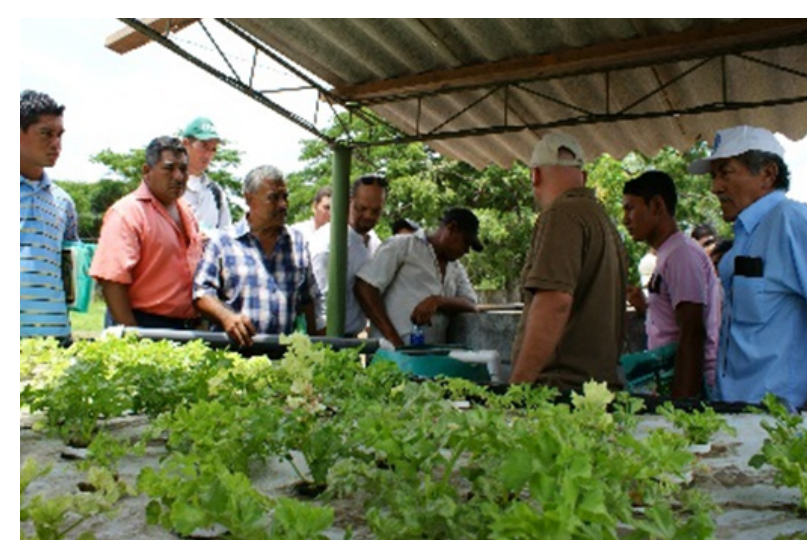

$\mathrm{E}$ stimados pequeños y medianos productores rurales de América Latina, llegó la hora de la verdad. Para poder solucionar sus problemas económicos ustedes saben, por experiencia propia, que de sus gobiernos es muy poco lo que pueden esperar; no necesariamente porque ellos no quieran apoyarlos sino porque no pueden hacerlo. Entre otras razones, porque las instituciones gubernamentales están muy debilitadas, desfinanciadas, muy politizadas y llenas de ineficiencias y rigideces burocráticas. Concretamente los gobiernos están perdiendo la capacidad operativa, financiera y política de resolver los problemas de los agricultores. Seguir esperando que los gobiernos resuelvan sus problemas por la vía del ineficaz paternalismo significa perder tiempo, porque tal posibilidad es ínfima por no decir nula. Por estas razones de fondo es necesario que ustedes mismos se encarguen de la solución de sus problemas, por más escasos que sean los recursos productivos que ustedes utilizan y por más modestos que sean los apoyos de sus gobiernos. El objetivo de este mensaje es demostrarles que, afortunadamente, ustedes mismos podrán hacerlo si se disponen a adoptar, algunas y ojalá todas, las 10 medidas descritas a continuación; porque ellas al ser de bajo costo y de fácil aplicación, están o estarán al alcance de ustedes, con la única condición de que reciban una adecuada orientación técnica para que ustedes sepan cómo aplicarlas; y si lo hacen de manera correcta ustedes prescindirán de los apoyos paternalistas de su gobiernos.
Las medidas que estoy proponiendo para que ustedes mismos puedan actuar como eficientes solucionadores de sus problemas son las siguientes:

Primera medida. La más imprescindible y eficaz decisión que ustedes necesitan tomar para que puedan empezar a solucionar sus problemas es la siguiente: EL CAMBIO DE ACTITUD DE LOS PRODUCTORES RURALES en el sentido de darse cuenta de lo siguiente: que las principales causas de sus problemas económicos no necesariamente residen en la insuficiencia de tierra, de crédito, de maquinaria; tampoco residen en la globalización de los mercados, en los tratados de libre comercio, en el neoliberalismo, en los subsidios que los gobiernos de los países ricos conceden a sus productores rurales. La causa más profunda del subdesarrollo rural que puede y debe ser eliminada por la via de una educación adecuada, reside en las ineficiencias/errores que la gran mayoría de los productores rurales comete, en todas las etapas de su negocio agrícola. Ineficiencias que están cometiendo no por culpa de ustedes evidentemente, sino que por culpa de nuestras disfuncionales e ineficientes instituciones educativas rurales ( las facultades de educación y escuelas normales que forman los futuros maestros de la educación básica, las escuelas primarias rurales, las facultades de ciencias agrarias y los servicios de extensión agrícola ). Y mientras estas instituciones educativas rurales no mejoren dramáticamente su 
desempeño, ustedes tendrán crecientes dificultades para tener rentabilidad en las actividades agrícolas y ganaderas.

Por esta razón de fondo les recomiendo que, en vez de seguir esperando, año trás año, por humillantes, efímeras e ineficaces migajas paternalistas, se organicen solidariamente con sus colegas agricultores y ganaderos para presionar y exigir que dichas instituciones educativas cumplan con su deber de ofrecerles una educación de excelente calidad, con el fin de que ustedes mismos sean los eficientes y permanentes solucionadores de sus problemas. Sin embargo, el mejoramiento de todo el sistema de educación rural será un proceso de larga duración y ustedes no pueden esperar porque necesitan volverse más eficientes y más productivos, inmediatamente. Debido a este carácter de urgencia les recomiendo que ustedes formen un grupo de productores y en conjunto contraten un extensionista competente que tenga la capacidad, más práctica que teórica, de volverlos más eficientes y más productivos. Si los recursos de ustedes no alcanzan para pagar el extensionista soliciten que la alcaldía municipal o alguna otra institución de apoyo agro contraten dicho extensionista y lo ponga disposición de ustedes; porque este asesoramiento técnico es imprescindible para que ustedes sepan qué y cómo hacer para adoptar, de manera correcta, esas medidas "eficientizadoras" del negocio agrícola.

Segunda medida. Ustedes necesitan aumentar, de manera muy significativa, sus actuales y bajísimos rendimientos promedio por hectárea y por animal, indicados a continuación en los ítems a, b, c, d, e, f. Porque en el mundo globalizado y altamente competitivo ustedes, sencillamente, no podrán sobrevivir económicamente:

a. Mientras sigan cosechando apenas 3500 kilogramos de maíz por hectárea, porque en vuestros propios países existen crecientes cantidades de maiceros que ya están cosechando ocho, doce y hasta dieciséis toneladas por hectárea

b. Mientras sigan cosechando apenas 2300 kilogramos de trigo por hectárea porque en varios países de América Latina existen trigueros que están cosechando más de siete toneladas por hectárea

c. Mientras sigan cosechando apenas 15000 kilogramos de papas por hectárea porque los paperos eficientes están cosechando cuarenta, cincuenta y hasta sesenta toneladas por hectárea.

d. Mientras sigan cosechando menos de 900 kilogramos de frejol/frijol por hectárea porque los productores eficientes de esta leguminosa, dentro y fuera de América Latina, ya están cosechando más de $3.000 \mathrm{~kg} / \mathrm{ha}$

e. Mientras sus vacas sigan pariendo un ternero a cada veinte meses y cada una de ellas produciendo apenas cuatro litros de leche al día; porque en todos los países latinoamericanos existen productores lecheros cuyas vacas tienen un parto a cada 13 meses y cada una de sus vacas ya está produciendo en promedio 40 litros de leche al día (diez veces más que el promedio latinoamericano)

f. Mientras sus novillos estén alcanzando el peso de faena/ abate a los 48 meses, porque van tener que competir con ganaderos mucho más eficientes cuyos novillos llegan al peso de faena a los 24 , a los 20 y hasta a los 18 meses.

Tercera medida. Gradualidad en la introducción de innovaciones para no necesitar de préstamos de los bancos ni de los usureros. Sin embargo, es evidente que ustedes no podrán lograr estos avances máximos en los rendimientos por hectárea y por animal de un solo golpe, sino que deben hacerlo de manera gradual, paso a paso. Deberán empezar adoptando las denominadas tecnologías de procesos/tecnologías de conocimiento (aquellas cuya aplicación/adopción depende mucho más del cómo hacer que del con qué hacer). Es decir ustedes deberán iniciar el aumento de la productividad aplicando aquellas muchas tecnologías de bajo o cero costo las que para ser adoptadas apenas requieren de conocimientos adecuados. Como por ejemplo: En la ganadería: antes del parto recoger la vaca a un local seco y limpio, desinfectar el ombligo del ternero recién nacido, garantizar que el ternero tome la cantidad correcta de calostro en las primeras cuatro horas de vida, adoptar medidas de higiene antes, durante y después del ordeño, vacunar y desparasitar los animales, aumentar la productividad y la calidad de las pasturas, si posible adoptar el pastoreo rotativo, almacenar alimentos ( como granos, ensilaje o heno ) para que los animales estén bien alimentados y productivos inclusive durante los períodos de escasez de pasturas, elaborar raciones balanceadas utilizando los ingredientes que ustedes mismos pueden producir en sus fincas, etc. En la agricultura: mantener la cobertura del suelo y jamás quemar los rastrojos, recoger los estiércoles para abonar la tierra, diversificar las especies producidas, hacer test de germinación antes de la siembra, sembrar y cosechar en el momento adecuado, sembrar con la cantidad correcta de plantas/matas por hectárea, sembrar en curvas de nivel, adoptar la rotación de cultivos y la extraordinaria tecnología agronómica denominada labranza cero, inocular las semillas de leguminosas, adoptar el manejo integrado de plagas para reducir los gastos con pesticidas, eliminar las malezas antes que ellas dañen el cultivo, etc. Estas tecnologías elementales recién propuestas son muy eficaces para empezar a aumentar la productividad en la agricultura y en la ganadería, pero ellas aún no son suficientes; sin embargo esto no llega a ser un problema insoluble. Porque después que ustedes adopten, de manera correcta, las medidas de esta primera etapa, en vez de obtener préstamos de los bancos, ustedes van generar dentro de sus propias y ahora más eficientes fincas los recursos financieros que serán necesarios para adquirir semillas mejoradas, fertilizantes químicos, pesticidas agrícolas, antiparasitarios y sales minerales; insumos que ustedes utilizarán en una segunda etapa de modernización productiva que, a 
su vez, les permitirá lograr un nuevo salto/incremento en la productividad y en los ingresos familiares. Recién después de cumplir estas dos etapas, será el momento adecuado para sembrar más hectáreas, ampliar el rodeo, introducir el riego, etc.; utilizando para tal fin los recursos financieros generados por ustedes mismos en sus propias fincas. Esto significa que una finca diversificada y más productiva puede funcionar como si fuese una agencia de crédito rural.

Cuarta medida Es mejor criar una menor cantidad de vacas y sembrar menos hectáreas de tierra para obtener de ambas una mayor productividad y rendimiento. Teniendo en cuenta que los recursos productivos que ustedes utilizan suelen ser escasos no les queda más remedio que volverlos mucho más productivos, aplicando tecnologías que les permitan producir más kilogramos por hectárea y por animal. Por esta razón les sugiero que críen apenas la cantidad de vacas que ustedes puedan alimentar adecuadamente, durante los 365 días del año, de modo que ellas puedan producir más leche y más crías. A modo de ejemplo, será más racional y económicamente más conveniente utilizar/ocupar apenas media o una hectárea de tierra con una pradera de alta productividad y con su producción alimentar adecuadamente una vaca genéticamente mejorada, desparasitada y sana para que produzca 20 litros de leche al día; en vez de ocupar 5 hectáreas de tierra escasa para mantener en ellas 5 vacas hambrientas, con mastitis y llenas de ecto y endoparásitos que producen 4 litros al día cada una, que es el promedio latinoamericano. Esta propuesta para mejorar los ingresos familiares a través del incremento de la productividad, además de imprescindible, es especialmente importante porque la mayoría de productores rurales es constituida por minifundistas; y por este razón de fondo necesitan estar capacitados para saber producir más y mejor, con menos recursos. Mantener una excesiva cantidad de vacas y otros animales hambrientos y con bajísimos índices zootécnicos es un error elemental y primario que está muy generalizado en el agro latinoamericano; es necesario y posible corregir esta ineficiencia.

Quinta medida No sigan sembrando monocultivos o "bicultivos" de granos básicos que producen una o dos cosechas al año, porque sus familias necesitan alimentarse y gastar durante los 365 días del año. Diversifiquen la producción agrícola y distribuyan/difieran las fechas de siembras (jamás siembren toda la superficie de un mismo cultivo en una misma fecha). A través de la diversificación ustedes producirán cosechas e ingresos en distintas épocas del año y con ello se volverán menos dependientes de los bancos y de los usureros. Adoptando dicha diversificación, y si el clima lo permite, ustedes podrán cultivar hortalizas de ciclo más corto para sacar varias cosechas al año; asimismo podrán producir diferentes especies de frutales para tener cosechas e ingresos también en distintas épocas del año, podrán criar pollos, conejos o cuyes, cerdos, tener algunas cabras o vacas lecheras; todo lo anterior con el propósito de generar alimentos y pequeños ingresos todos los días del año. Los productores más despiertos de vacunos, cabras y ovejas deberán, en primerísimo lugar, mejorar la productividad y la calidad de las pasturas para volverse menos dependientes de los gastos con la adquisición de raciones balanceadas industrializadas, cuyos precios son muy elevados. Los productores más despiertos de ganado lechero, cerdos y aves deberán producir en sus propias fincas (o en tierras de terceros) los ingredientes (maíz, soya, alfalfa, girasol, yuca, camote, etc.) y transformarlos en raciones balanceadas de muy bajo costo. Cuando ustedes cosechen estos seis ingredientes recién mencionados jamás los vendan al primer intermediario que aparezca en la finca; transfórmenlos en raciones balanceadas y "véndanlas" a sus propias vacas lecheras, cerdos y pollos, para que estén adecuadamente alimentados, con costos muy bajos. Adoptando de manera correcta estas medidas tan elementales seguramente ustedes mejorarán los ingresos familiares.

Sexta medida. Realicen, también en forma gradual, la sustitución de cultivos/reconversión productiva. Ella consiste en reemplazar las especies actualmente cultivadas por los productores pobres y adquiridas por los consumidores pobres; y en su lugar producir rubros que son adquiridos por los consumidores ricos. Porque es muy difícil que un agricultor con menos de 5 hectáreas de tierra, sembrando yuca, papas, camote, calabaza, arroz, frejol u otros granos básicos, pueda sobrevivir económicamente teniendo tan minúscula superficie de terreno; por más elevados/altos que sean sus rendimientos por hectárea. Porque estos seis productos recién mencionados rinden poquísimos ingresos por hectárea en virtud de que son consumidos principalmente por los pobres que no pueden pagar precios más altos. Por este motivo es conveniente reemplazarlos por otros rubros/productos más sofisticados que son adquiridos por los consumidores ricos. A modo de ejemplos, adoptando dicha reconversión ustedes podrán producir algunas de las siguientes especies: espárragos, brócolis, tomates-cereza, champiñones, melones, chirimoyas, mangos, aguacates/paltas, guanábanas, frutillas/ fresas, pitahayas, granadillas, piñas, higos, hortalizas orgánicas, pollos camperos, huevos de codornices, maíz y arveja verdes para consumir frescas ( como chauchas ), miel de abejas, flores, plantas medicinales y ornamentales, plantones de frutales, etc. Este reemplazo/reconversión productiva, es una otra alternativa muy realista, pragmática y eficaz para contrarrestar la insuficiente superficie de tierra que poseen los minifundistas; ídem para mejorar sus ingresos sin necesidad de contar con ayudas externas a sus fincas.

Séptima medida. Reducir las (lamentables porque son evitables) pérdidas de granos, hortalizas y frutas. En los granos ustedes podrán evitar la incidencia de mico-toxinas y 
los daños provocados por gorgojos y roedores. Asimismo podrán reducir las pérdidas de hortalizas y frutas que abundan en las épocas de cosecha y se pierden por no transformarlas en las muy apreciadas conservas artesanales tipo pickles, pulpas de frutas, jugos, jaleas, frutas en almíbar y/o mermeladas; o por no desecar/deshidratar las frutas, exponiéndolas directamente al sol (si el clima lo permite) o utilizando secadores solares. Algunas frutas secas/deshidratadas tienen excelente sabor, gran aceptación y elevados precios en los mercados; tales como: damascos, piñas, ciruelas, mangos, higos, papayas y bananas.

Octava medida. "Maquillar" las cosechas antes de comercializarlas. Ustedes también podrán adoptar algunas medidas más elementales para mejorar la presentación visual de sus cosechas antes de venderlas, tales como: lavarlas/limpiarlas, clasificarlas por tamaño, fraccionarlas y envasarlas. Utilizando la mano de obra familiar podrán hacer un "maquillaje" tan elemental como el que realizan los supermercados antes de vender las frutas, hortalizas y raíces (clasificándolas, poniéndolas sobre bandejas de polietileno y cubriéndolas con una película transparente). En el caso de los frejoles/lentejas/ garbanzos/arvejas/o cacahuates sin cáscara (seleccionándolos y envasándolos en bolsas plásticas 500 o 1.000 gramos). Y gracias a estos maquillajes tan sencillos y de bajísimo costo, los supermercados suelen duplicar o triplicar los precios de venta. Entonces si los empleados de los supermercados pueden ser capacitados para mejorar la presentación visual de estos productos primarios, es evidente que las familias rurales también podrán ser capacitadas para hacerlo.

Sin embargo es necesario reconocer que algunas de las medidas hasta aqui propuestas requieren inversiones de costo más elevado, que cada pequeño productor no podrá realizarlas, en forma individual. Por tal motivo para hacer factible/ facilitar la adopción de esta propuesta será conveniente que ustedes adopten la novena y la décima medida descritas a continuación.

Novena medida. Adoptar la verticalización/integración vertical del negocio agrícola. Los alemanes utilizan el siguiente refrán que es muy agresivo pero que contiene una profunda y lamentable verdad: "Es mejor vivir del agricultor que de la agricultura". A propósito, es interesante observar que, con la excepción de ustedes los productores rurales, casi ninguno de los demás integrantes de las largas cadenas agroalimentarias se dedica a la etapa de producción agrícola o ganadera propiamente tal. Porque todos estos otros integrantes ya se dieran cuenta de que la etapa de producción agrícola y ganadera propiamente tal, es un negocio altamente riesgoso y poco rentable. Por esta razón ustedes no deben seguir encargándose apenas de la etapa más pobre del negocio agrícola, que es la etapa que va desde la siembra hasta la cosecha. Porque esta etapa es la que exige más trabajo, es la menos rentable y es la que está más expuesta/vulnerable a riesgos de clima, plagas/enfermedades y de mercadeo. Entonces, ustedes además de seguir dedicándose a la etapa de producción propiamente tal, deben empezar a encargarse de algunas etapas ricas del negocio agrícola. Es decir, a aquellas que ocurren antes de la siembra (producir raciones balanceadas); y también de algunas etapas que ocurren después de la cosecha (incorporar valor agregado a sus cosechas y comercializarlas con menor intermediación). Con el doble propósito de reducir al mínimo los costos por kilogramo producido y de incrementar al máximo los ingresos obtenidos por kilogramo comercializado. Esta es la "receta" más eficaz para mejorar la rentabilidad en el negocio agrícola.

A modo de ejemplo, los productores de cerdos y aves podrán producir en sus fincas los ingredientes con los cuales se fabrican las raciones balanceadas y fabricarlas ustedes mismos y con estas raciones balanceadas "caseras" alimentar a sus cerdos y aves; y, si posible, procesar/industrializar en forma artesanal los cerdos/capones transformándolos en jamones, salames, panceta, longanizas, morcillas y chicharrones. Porque si ustedes no empiezan a practicar dicha "verticalización"/integración vertical del negocio agrícola, quienes seguirán apropiándose cada vez más de las riquezas que ustedes generan, serán los siguientes: los industriales y comerciantes que fabrican y revenden las raciones balanceadas, los intermediarios que compran las cosechas, los agroindustriales que las transforman/incorporan valor agregado, las fraccionan y envasan y finalmente las gigantescas redes de supermercados que las "maquillan" y comercializan. Al tener tantos "socios" con quienes están compartiendo las riquezas que ustedes producen en sus fincas, no es de sorprender la distorsión/injusticia que describiré a continuación.

Varios recientes estudios indican que, en promedio, los productores rurales de América Latina reciben apenas entre el $15 \%$ y el $20 \%$ de los precios que los consumidores pagan por los alimentos en los supermercados, verdulerías, fruterías, panaderías y carnicerías. Además, uno de estos estudios pronostica que, de no adoptarse medidas correctivas para detener esta injusta distorsión, dentro de unos tres o cuatro años los productores rurales recibirán apenas el 10\%. De los otros $90 \%, 85 \%$ u $80 \%$ se apropiarán, sin merecer, quienes menos trabajaron, quienes no produjeron ninguna riqueza y quienes no se expusieron a mayores riesgos. Y este es el tema que abordaré en el próximo ítem 10 de esta exposición e indicaré que el "remedio" para que los agricultores se apropien de un porcentaje más justo de las riquezas que generan en sus fincas se llama cooperativismo/asociativismo/solidaridad; tal como ya están aplicando con extraordinario éxito muchísimos productores rurales especialmente en el sur de Brasil, Argentina y Paraguay. 
Décima medida. El individualismo está causando un gran daño económico a los pequeños y medianos productores rurales. Por esta razón les recomiendo que depongan esta actitud de una vez, porque sin que ustedes se den cuenta, el individualismo está "erosionando" sus ingresos y destruyéndolos económicamente. Con tal propósito les recomiendo juntarse con sus vecinos confiables y formar inicialmente pequeños grupos solidarios/cooperativos, para realizar en conjunto con ellos algunas actividades que económicamente no les conviene o no es posible realizar en forma individual. A propósito observen, a través de estos tres próximos ejemplos, cómo en la actualidad ustedes mismos, sin quererlo, están actuando en contra de sus propios intereses económicos:

Primer ejemplo - Ustedes pagan precios innecesariamente altos por los insumos porque los adquieren siempre en forma individual, en pequeñas cantidades, del último eslabón de una larga cadena de intermediación y con alto valor agregado (reitero que las raciones balanceadas que ustedes compran del último intermediario, probablemente fueron fabricadas por una gran multinacional utilizando los ingredientes que salieron de vuestras propias fincas o comunidades). Además ustedes adquieren las semillas, fertilizantes y pesticidas, en la peor época del año cuando todos los productores acuden a comprarlos, la oferta disminuye y los precios suben.

Segundo ejemplo - Pero ustedes mismos cuando venden sus cosechas hacen lo contrario de lo que hicieron cuando compraron los insumos; porque venden sus cosechas al primer intermediario que aparece en la finca, las comercializan al por mayor tal como las cosecharon y sin incorporar valor agregado. Además las venden en la peor época del año, cuando todos los productores necesitan vender para quitar sus deudas y pocos compradores desean adquirirlas; y, por estas razones obtienen precios innecesariamente bajos en la comercialización de las riquezas que producen. Observen que el individualismo los volvió extremadamente frágiles y los condujo a la siguiente paradoja: cuando ustedes compran los insumos adoptan la actitud convencional de preguntar al vendedor ¿cuánto cuesta? Pero cuando ustedes se convierten en vendedores de sus cosechas, en vez de fijar/determinar el precio de venta, ustedes siguen preguntando ¿cuánto me pagan? Es decir, por causa del individualismo, ustedes nunca son formadores de precios, sino que siempre son pasivos tomadores de precios; ustedes son frágiles/débiles porque cometen el error de no fortalecerse y no organizarse con sus vecinos para poder apropiarse de las riquezas que producen.

Tercer ejemplo - Muchos productores suelen endeudarse fuerte, excesiva e innecesariamente para poseer maquinaria individual de altísimo costo, que la utilizan durante 5 o 10 días al año y que "descansa" los otros 360 o 355 días. Entonces, hipotéticamente y a modo de ejemplo, será mejor que un grupo de 10 pequeños productores tenga un buen tractor, una buena sembradora, una buena cosechadora, una buena pulverizadora y una buena trituradora de granos y mescladora para elaborar sus propias raciones balanceadas; y que esa maquinaria brinde servicios a todos los 10 integrantes del grupo solidario. Desafortunadamente esto no ocurre porque cada agricultor, motivado por muy simpáticos y convincentes vendedores, se convence que necesita poseer una cosechadora de granos en forma individual (generalmente las cosechadoras individuales se justifican técnicamente apenas para aquellos agricultores que tengan superficies sembradas superiores a 300 hectáreas. Esta equivocada decisión suele generar consecuencias económicamente desastrosas en contra de ustedes mismos. Porque, en muchísimos casos, el dinero que ustedes gastaron para adquirir innecesariamente la maquinaria individual y sobredimensionada que permanecerá subutilizada, es el dinero que, más adelante, les hará falta para gastos muchísimo más indispensables/imprescindibles, como por ejemplo: comprar los insumos necesarios para aumentar la productividad en la agricultura (semillas mejoradas, fertilizantes, inoculantes, pesticidas); ídem para mejorar el desempeño de la ganadería (mejoramiento de las pasturas ojalá con fertilizaciones y riego, conservación de forrajes para los períodos de escasez, vacunas, semen, antiparasitarios, sales minerales). Observen que debido a este individualismo, aparentemente inofensivo, ustedes están adoptando estos tres procedimientos, todos ellos contrarios a sus propios intereses económicos. Abran los ojos, depongan esta autodestrucción y empiecen a practicar la solidaridad; antes que sea demasiado tarde.

Luego de analizar críticamente estas diez medidas ustedes podrán constatar/confirmar lo siguiente: que la mayoría de los problemas económicos de la mayoría de los productores rurales son causados por errores elementales y primarios que los productores rurales cometen por falta de conocimientos/habilidades/actitudes, también elementales y primarios, que nuestro sistema de educación rural no les proporcionó. Entonces si los gobiernos nacionales latinoamericanos, tal como nos han demostrado en los últimos cincuenta años, no tienen la más remota posibilidad de resolver, por la vía del paternalismo, todos los problemas de todos los productores rurales, año tras año, deberán como mínimo y prioritario proporcionar a los productores rurales y a sus familias el más imprescindible y eficaz insumo del mundo moderno: una educación de excelente calidad orientada a formar ciudadanos más autodependientes y autogestionarios, más emprendedores y más solidarios con sus vecinos para que puedan solucionar sus problemas y progresar en la vida con mínima dependencia del paternalismo estatal. 